\section{Role of the gut microbiome in mediating lactose intolerance symptoms}

Misselwitz et al recently reviewed the multifactorial aspects of lactose intolerance (LI). ${ }^{1}$ Their work highlights the known effects of genetic makeup and dietary patterns in the occurrence of gastrointestinal symptoms in LI individuals. The authors define LI as the occurrence of gastrointestinal complaints on lactose exposure and discuss the wide variety of symptoms among LI patients. ${ }^{1}$ Regarding lactose metabolism, Misselwitz et al mention the influence of the gut microbiome, in particular that Bifidobacterium or other lactose-fermenting bacteria are reported to affect the levels of lactose in the gut. However, the impact of the gut microbiome on the occurrence of gut-related LI symptoms remains unclear.

We previously observed that the Bifidobacterium abundance in the adult human gut depends on the interaction between LI genetic variants and dairy intake. ${ }^{2}$ This observation complements other findings indicating a mutual relationship between the gut microbiome and host lactose metabolism. $^{3-8}$ However, these earlier analyses did not consider the occurrence of gastrointestinal symptoms. This inspired us to investigate whether the interplay of dairy consumption and Bifidobacterium affects the occurrence of gastrointestinal complaints in LI individuals.

We analysed data on gut complaints, genetics, gut microbiome and diet in 959 participants of the Lifelines-DEEP Dutch population cohort. We classified LI genetic status based on the presence of the functional variant rs4988235 associated with
A

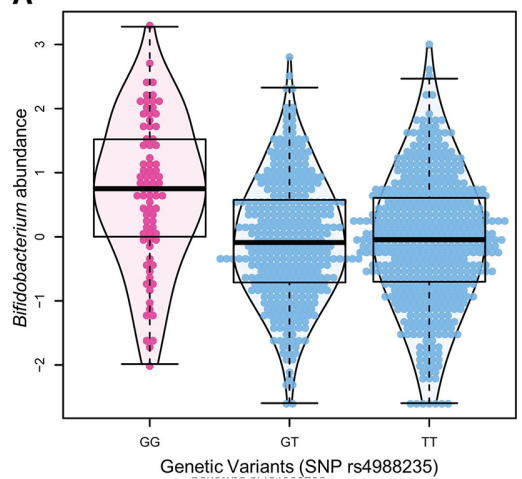

C

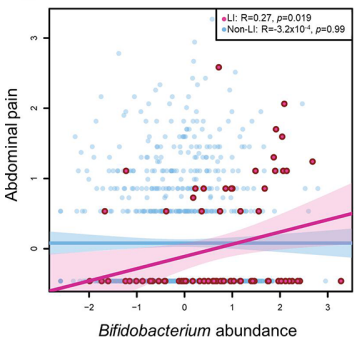

D

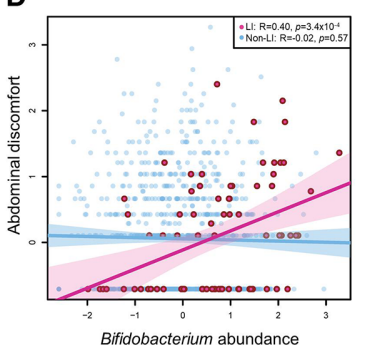

E

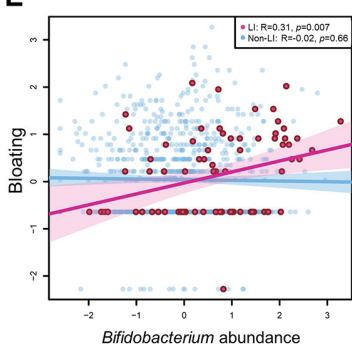

Figure 1 Bifidobacterium abundance and gut complaints in lactose intolerant (LI) individuals. (A) Higher Bifidobacterium abundance in individuals with the LI genotype (homozygous G/G) compared with the lactose tolerant genotypes (G/T and T/T) for SNP rs4988235. (B) In LI individuals, Bifidobacterium abundance is significantly associated with the total gastrointestinal complaints score $(\mathrm{p}=0.003)$. More specifically, Bifidobacterium abundance shows positive correlations with (C) abdominal pain, (D) gastrointestinal discomfort and (E) bloating. all numerical factors were subjected to rank-based inverse normal transformation.

LI in Caucasian populations, as described earlier, ${ }^{2}$ and we found the LI recessive genotype $(\mathrm{G} / \mathrm{G})$ in 81 individuals $(8.4 \%$ of the cohort). We investigated microbiome composition using shotgun metagenomic sequencing of faecal samples ${ }^{2}$ and selected the relative abundance of the Bifidobacterium genus for our analysis. Dietary intake, including milk and other dairy products, was assessed using a food frequency questionnaire. Total dairy consumption, in

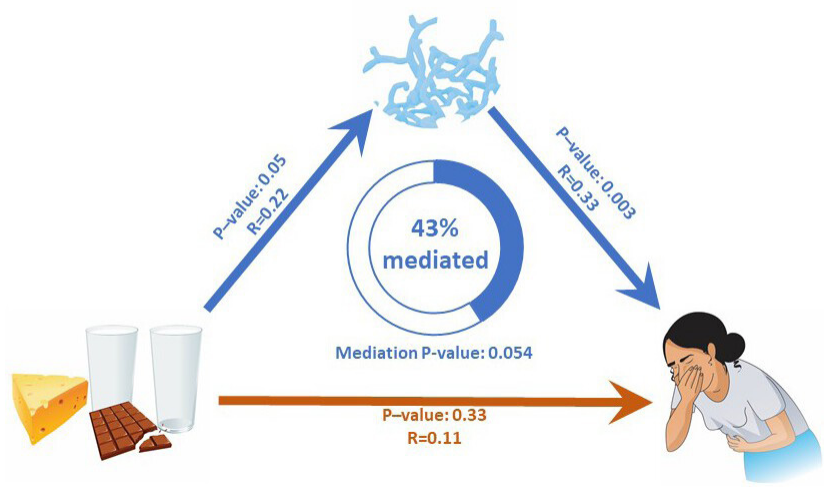

Figure 2 Analysis of the direct and indirect associations between milk intake, Bifidobacterium abundance and gut complaints. Statistically significant associations are shown with blue arrows. The non-significant correlation is shown by the red arrow. The presence of gut complaints related to the consumption of dairy products in LI individuals is largely mediated by Bifidobacterium abundance. $\mathrm{LI}$, lactose intolerance.

grams per day, was retrieved using the Dutch Food Composition tables. ${ }^{9}$ Notably, there were no reports of complete avoidance of dairy consumption among patients with LI. Lastly, gut complaints were assessed via a 7-day questionnaire where participants were asked to rank (from 1 to 5) their daily level of gastrointestinal discomfort in six categories: 'abdominal discomfort', 'bloating', 'burping', 'abdominal pain', 'flatulence' and 'nausea'. The sum of the mean daily scores from each category was used as the overall score of gastrointestinal complaints.

As reported previously, an increased Bifidobacterium abundance was observed in LI individuals compared with non-LI individuals $\left(p_{\text {Wilcox }}=4.56 \times 10^{-9}\right)$ (figure 1A) and was positively correlated with dairy intake in the LI group $(\mathrm{R}=0.22, \mathrm{p}=0.05)$ but not in the non-LI group $(\mathrm{R}=0.02$, $\mathrm{p}=0.48)$. No significant difference in dairy consumption was found between the LI and non-LI groups $\left(p_{\text {Wilcox }}=0.31\right)$. In LI individuals, we observed a positive correlation between Bifidobacterium abundance and total gut complaints score $(\mathrm{R}=0.33, \mathrm{p}=0.003)$ (figure $1 \mathrm{~B})$. Of the six specific gut complaints, Bifidobacterium abundance was positively correlated with abdominal pain, discomfort and 
bloating (figure $1 \mathrm{C}-\mathrm{E}$ ) but not with any other complaints (all $\mathrm{p}>0.26$ ). We then performed a mediation analysis to address how dairy intake and Bifidobacterium abundance would influence the occurrence of symptoms in LI individuals. Interestingly, we found that the association between dairy intake and gastrointestinal complaints was partially mediated by Bifidobacterium abundance (Prop mediated $=43 \%, \mathrm{p}=0.054$ ) (figure 2 ).

Our results provide evidence that specific gut symptoms, experienced by LI patients, might be the result of Bifidobacterium abundance in the gut, rather than a direct effect of lactose intake. This work supports initial reports where metabolic products of lactose-fermenting bacteria may be related to LI symptom occurrence. $^{7810}$

M F Brandao Gois $\odot,{ }^{1}$ Trishla Sinha, ${ }^{1}$ Johanne E Spreckels $\odot$, 1 Arnau Vich Vila $\odot$, ${ }^{1,2}$ Laura A Bolte $\odot,{ }^{1,2}$ Rinse K Weersma $\odot,^{2}$ Cisca Wijmenga, ${ }^{1}$ Jingyuan $\mathrm{Fu}^{1,3}$ Alexandra Zhernakova, ${ }^{1}$ Alexander Kurilshikov ${ }^{1}$

${ }^{1}$ Department of Genetics, University Medical Centre Groningen, Groningen, The Netherlands

2Department of Gastroenterology and Hepatology, University Medical Centre Groningen, Groningen, The Netherlands

${ }^{3}$ Department of Pediatrics, University Medical Centre Groningen, Groningen, The Netherlands

Correspondence to Dr Alexander Kurilshikov, Department of Genetics, University Medical Centre Groningen, Groningen 30001, 9700, The Netherlands; a.m.kurilshchikov@umcg.nl

Twitter Alexandra Zhernakova @SashaZhernakova

Acknowledgements We thank Katherine McIntyre for editing this letter. The researchers participated in this project are supported by Netherlands Heart Foundation (IN-CONTROL CVON grant 2012-03 and 2018-27); the Netherlands Organisation for Scientific Research (NWO) (NWO-VIDI 864.13.013 to JF, NWOVIDI 016.178.056 to AZ and NWO Spinoza Prize SPI 92-266 to (W); the NWO Gravitation Netherlands Organ-on-Chip Initiative to JF and CW, the NWO Gravitation Exposome-NL (024.004.017) to JF, AK and AZ; the European Research Council (ERC) (FP7/2007-
2013/ERC Advanced Grant 2012-3 22698 to CW, and ERC Starting Grant 715772 to AZ). TS holds scholarships from the Junior Scientific Masterclass, University of Groningen.

Contributors $A K$ and $A Z$ formulated the concept and design of the study. MFBG performed the data analysis. $M F B G, T S, A V V$, JES, LAB and AK were involved in the interpretation of the results. The data for the study was collected by RKW, JF, CW and AK. MFBG, AZ and AK have written the manuscript, with assistance and revision by all coauthors. All coauthors have critically revised this letter and approved the final version for publishing.

Funding The researchers participated in this project are supported by Netherlands Heart Foundation (IN-CONTROL CVON grant 2012-03 and 2018-27); the Netherlands Organisation for Scientific Research (NWO) (NWO-VIDI 864.13.013 to JF, NWO-VIDI 016.178.056 to AZ and NWO Spinoza Prize SPI 92-266 to CW); the NWO Gravitation Netherlands Organ-on-Chip Initiative to JF and CW, the NWO Gravitation Exposome-NL (024.004.017) to JF, AK and $A Z$; the European Research Council (ERC) (FP7/20072013/ERC Advanced Grant 2012-3 22698 to CW and ERC Starting Grant 715772 to AZ). TS holds scholarships from the Junior Scientific Masterclass, University of Groningen.

Competing interests None declared.

Patient and public involvement Patients and/or the public were not involved in the design, or conduct, or reporting, or dissemination plans of this research.

Patient consent for publication Not required.

Provenance and peer review Not commissioned; internally peer reviewed.

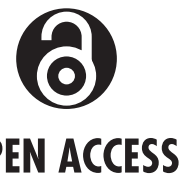

Open access This is an open access article distributed in accordance with the Creative Commons Attribution 4.0 Unported (CC BY 4.0) license, which permits others to copy, redistribute, remix, transform and build upon this work for any purpose, provided the original work is properly cited, a link to the licence is given, and indication of whether changes were made. See: https://creativecommons.org/licenses/by/ 4.0\%.

(C) Author(s) (or their employer(s)) 2021. Re-use permitted under CC BY. Published by BMJ.

\section{Check for updates}

To cite Brandao Gois MF, Sinha T, Spreckels JE, et al. Gut Epub ahead of print: [please include Day Month Year]. doi:10.1136/gutjnl-2020-323911

Received 19 December 2020

Revised 13 February 2021

Accepted 22 February 2021

Gut 2021;0:1-2. doi:10.1136/gutjnl-2020-323911

ORCID iDs

M F Brandao Gois http://orcid.org/0000-0001-79182481

Johanne E Spreckels http://orcid.org/0000-0002-87111736

Arnau Vich Vila http://orcid.org/0000-0003-4691-5583 Laura A Bolte http://orcid.org/0000-0001-6036-0831

Rinse K Weersma http://orcid.org/0000-0001-79287371

\section{REFERENCES}

1 Misselwitz B, Butter M, Verbeke K, et al. Update on lactose malabsorption and intolerance: pathogenesis, diagnosis and clinical management. Gut 2019;68:2080-91.

2 Bonder MJ, Kurilshikov A, Tigchelaar EF, et al. The effect of host genetics on the gut microbiome. Nat Genet 2016:48:1407-12.

3 Goodrich JK, Davenport ER, Beaumont M, et al. Genetic determinants of the gut microbiome in UK twins. Cell Host Microbe 2016;19:731-43.

4 Goodrich JK, Davenport ER, Clark AG, et al. The relationship between the human genome and microbiome comes into view. Annu Rev Genet 2017:51:413-33.

5 Szilagyi A, Ishayek N. Lactose intolerance, dairy avoidance, and treatment options. Nutrients 2018;10:1994.

6 Suzuki TA, Ley RE. The role of the microbiota in human genetic adaptation. Science 2020;370:eaaz6827.

7 He T, Venema K, Priebe MG, et al. The role of colonic metabolism in lactose intolerance. Eur J Clin Invest 2008;38:541-7.

8 He T, Priebe MG, Harmsen HJM. Colonic fermentation may play a role in lactose intolerance in humans 1 , 2006. Available: https://academic.oup.com/jn/article/ 136/1/58/4664164

9 NEVO 2011. RIVM Bilthoven. The Netherlands, 2011.

10 Staudacher HM, Lomer MCE, Farquharson FM, et al. A diet low in FODMAPs reduces symptoms in patients with irritable bowel syndrome and a probiotic restores Bifidobacterium species: a randomized controlled trial. Gastroenterology 2017;153:936-47. 